
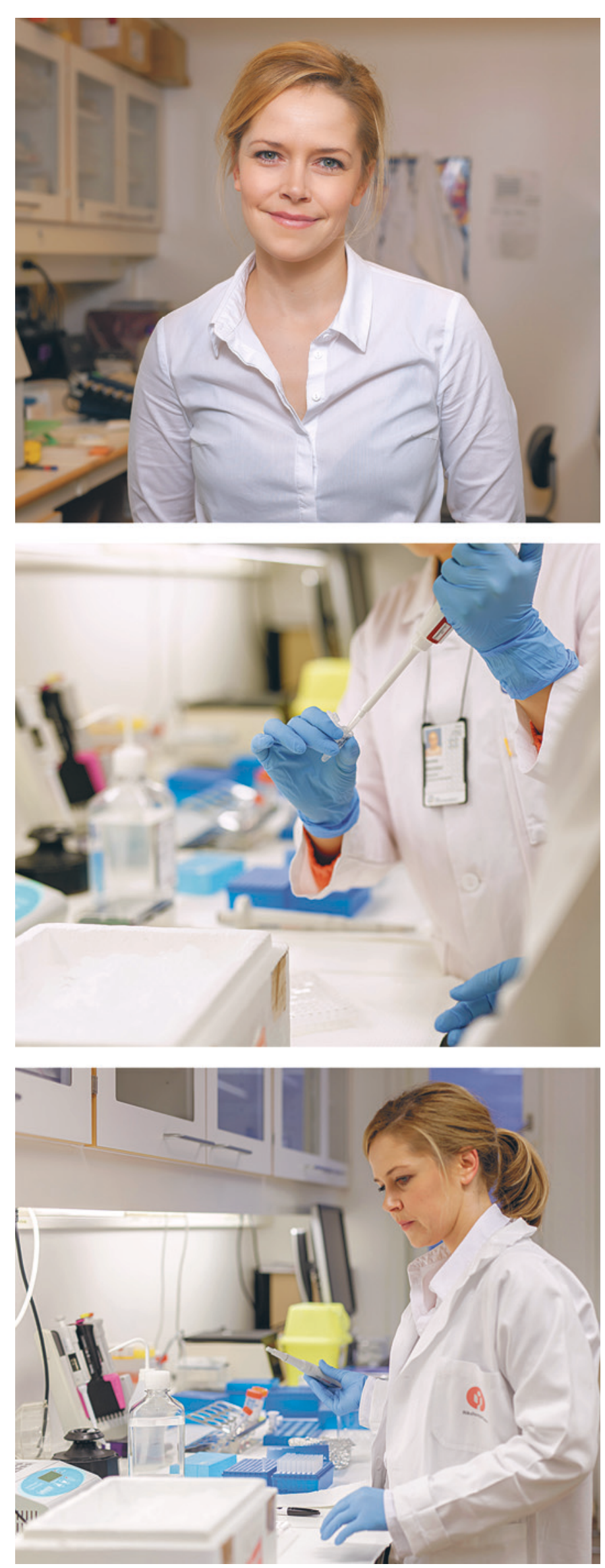

Foto: Niklas Lello

\section{Start resolusjonen}

\author{
Linn Elisabeth Fosshaug er lege i spesialisering og \\ stipendiat ved Diakonhjemmet sykehus og Institutt for \\ indremedisinsk forskning, Oslo universitetssykehus, \\ Rikshospitalet. I 2015 hospiterte hun i gruppen til pro- \\ fessor Serhan ved Harvard Institute of Medicine.
}

\section{Skjer det noe interessant innen hjerteforskning for tiden?}

Aterosklerose regnes i dag som et typisk eksempel på en kronisk betennelse eller inflammasjonssykdom hvor det oppstår en «ond sirkel» mellom betennelse og lipider. Inflammasjonsreaksjonen som for eksempel oppstår i forbindelse med et hjerteinfarkt, er imidlertid også en vital og viktig reparasjonsprosess. Problemene oppstår når reaksjonen blir for langvarig, for sterk eller begge deler. Årsaken til hvorfor betennelsesprosessen opphører eller ikke opphører har tidligere vært et uavklart spørsmål. Imidlertid vet vi nå at dette ikke er en passiv prosess, men at betennelsen avsluttes via en nøye regulert prosess som vi kaller resolusjon. Fravær av resolusjon er et nytt begrep som kan forklare mye av ubalansen vi ser ved inflammasjonsreaksjoner som går over i kronisk form. En rekke metabolitter er involvert i resolusjonsprosessen, spesielt viktige er omega-3-derivatene «specialized pro-resolving lipid mediators» (SPMs) som er vist aktivt å kunne initiere resolusjon. I hjerte- og karsystemet har manglende resolusjon vist seg å være en del av sykdomsbildet $\mathrm{i}$ aterosklerose, trombedanning og hjertesvikt. Resolusjonskonseptet åpner for nye behandlingsmuligheter ved sykdommer hvor inflammasjon er en viktig del av patofysiologien, uten å påvirke den viktige jobben kroppen gjør når den reparerer vev.

\section{Kan du anbefale en ny og interessant artikkel?}

Resolusjon av inflammasjon er et relativt nytt begrep som de fleste ikke kjenner godt til i klinisk praksis, som er relevant for mange sykdommer, og som har stort potensial for nye terapeutiske angrepspunkter. Mangel på inflammatorisk resolusjon i aterosklerose er godt dokumentert og fint oppsummert av Peter Libby og medarbeidere i artikkelen Inflammation and its resolution as determinants of acute coronary syndromes (1).

\section{Hva er ditt favoritthjelpemiddel på jobb?}

Det må være kollegene mine! Når man kommer ny inn i en forskningsgruppe eller et nytt fagfelt, er man helt og totalt avhengig av kunnskapen og velviljen til forskerkolleger og veiledere. Appen Molarity (2) fra Sigma er også helt uvurderlig for en stakkars lege som ikke har tenkt på mol, molar og konsentrasjoner siden kjemifaget på videregående.

\section{Litteratur}

1. Libby P, Tabas I, Fredman G et al. Inflammation and its resolution as determinants of acute coronary syndromes. Circ Res 2014; 114: 1867-79.

2. Sigma. Appen Molarity. http://sigmaaldrich.com/chemistry/ stockroom-reagents/learning-center/technical-library/ molarity-calculator.html (30.1.2017).

Har du tips til personer vi kan intervjue? Ta kontakt med lisa.dahlbak.jacobsen@tidsskriftet.no 